\title{
Fertilization competence and sperm size variation in sperm-heteromorphic insects
}

\author{
G. BERNASCONI ${ }^{1,2, *}$ and B. HELLRIEGEL ${ }^{3,4}$ \\ ${ }^{1}$ Institute of Environmental Sciences, University of Zurich, Switzerland; ${ }^{2}$ Department of Ecology and \\ Evolution, University of Lausanne, Switzerland; ${ }^{3}$ Institute for Applied Mathematics, University of \\ Bonn, Germany (*author for correspondence, tel.: + 41-21-692-4217; fax: + 41-21-692-4265; \\ e-mail: giorgina.bernasconi@unil.ch); ${ }^{4}$ Present address: Institute for Advanced Study,Wallotstrasse \\ 19, 14193 Berlin, Germany
}

Received 27 May 2004; Accepted 13 December 2004

Co-ordinating editor: Hurst

\begin{abstract}
Between species, variation in sperm size has been related to male-female coevolution and male-male competition. In contrast, variation within species is poorly understood. A particular case of intraspecific sperm-size variation occurs in sperm-heteromorphic species, where males produce distinct sperm morphotypes, usually only one of which is fertile. This allows to investigate sperm size variation under different selection regimes. Nonfertile morphotypes, whose role is aside from fertilization, may have other functions, and this may be reflected by changes in developmental processes and a different phenotype compared to fertile sperm. We show that the intraspecific coefficient of variation in sperm length is up to four times lower for fertile than nonfertile morphotypes across 150 sperm-heteromorphic species (70 butterfly, 71 moth, 9 diopsid fly species). This is in agreement with a previous study on 11 species in the Drosophila obscura group. Significantly lower variation in fertile than nonfertile sperm morphometry may result from fertilization-related selection for optimal sperm size, novel functions of nonfertile sperm, or from tighter control of fertile sperm development. More data are needed to clarify the consequences and adaptive significance of within-morph variation, and its consistent pattern across sperm-heteromorphic insects.
\end{abstract}

Key words: fertilization, insect, levels of selection, meta-analysis, sperm morphology, sperm morphometry, sperm size

\section{Introduction}

Sperm cells carry the paternal genome to unification with the ovum. Despite this single function, sperm cells vary in size and shape. The diversity of sperm types suggests that they evolve in response to selective forces arising in the environment where fertilization and competition occur (Jamieson, 1987; Simmons, 2001). Fertilization often occurs in a hostile environment (be it the internal female reproductive tract or the external environment), and in competition with sperm from the same or rival males (Sivinski, 1984). Post-copulatory competition among sperm from rival males occurs in many taxa 
(Birkhead and Møller, 1998; Bernasconi et al., 2004) and has been predicted to affect optimal sperm number and size (Parker, 1982, 1990). Comparative studies indeed show that variation in sperm morphometry between species is associated with the intensity of male-male competition (Gomendio and Roldan, 1991; Briskie and Montgomerie, 1992; Gage, 1994; Johnson and Briskie, 1999; Anderson and Dixson, 2002), but also with female reproductive tract morphology (Dybas and Dybas, 1981; Briskie and Montgomerie, 1992; Pitnick et al., 1999; Presgraves et al., 1999; Morrow and Gage, 2000).

In contrast, variation within species (Ward, 1998; Hellriegel and Blanckenhorn, 2002) and within individual males is much less understood (Morrow and Gage, 2001a). Yet, within-male variation can result in distinct sperm morphotypes in a variety of taxa including gastropodos, spiders, centipedes and insects (Swallow and Wilkinson, 2002). In sperm-heteromorphic taxa, as a rule only one sperm morph seems to participate in fertilization (Snook and Karr, 1998; Swallow and Wilkinson, 2002). Why some of the sperm forego own reproduction remains unclear. Several hypotheses have been proposed for the evolution of sperm heteromorphism in insects (Simmons, 2001; Swallow and Wilkinson, 2002). Nonfertilizing sperm may result from developmental errors, facilitate transport and capacitation of fertilizing sperm, be a form of parental investment (e.g. by provisioning the fertilizing sperm, the zygote or the female), act in inter-ejaculate competition by displacing or inactivating rival sperm, or be a cheap filler to delay female remating, as in the butterfly Pieris napi (Cook and Wedell, 1999). Sperm heteromorphism may also serve more than one function (Simmons, 2001; Swallow and Wilkinson, 2002).

That one sperm morph is, as a rule, excluded from fertilization, allows to investigate variation among a male's gametes under different selection regimes. For fertile sperm, the fertilization environment, the intensity of competition with sperm of rival males and possibly also with sperm within the same ejaculate, exert selection pressure on traits that increase the probability of successful fertilization (Sivinski, 1980; Parker and Begon, 1993; Haig and Bergström, 1995). Neither selection for fertilization-related traits nor the potential for intra-ejaculate competition apply to nonfertile sperm, whose individual interests are silenced by deterioration of genetic material early during development, or by fertilization incompetence. Even in groups where the function of nonfertile sperm can be related to inter-ejaculate competition and delaying of female remating (He and Miyata, 1997; Cook and Wedell, 1999; Morrow and Gage, 2000; Wedell, 2001), nonfertile sperm are released from selection and constraints directly related to fertilization competence (Snook, 1997). In a metaanalysis including butterflies (Gage, 1994), moths (Morrow and Gage, 2000) and stalk-eyed flies (Presgraves et al., 1999) we show that size variation is significantly different between sperm morphs, and that the fertile sperm morph is characterized by smaller variation than the nonfertile sperm morph. 


\section{Materials and methods}

To investigate the association between the amount of variability in sperm morphology and fertilization competence, we calculated intraspecific variation coefficients (see below) for published data on sperm length of fertile and nonfertile sperm. Our analysis includes three insect taxa for which data on a large sample of sperm-heteromorphic species were available (butterflies: Gage, 1994; moths: Morrow and Gage, 2000; stalk-eyed flies: Presgraves et al., 1999). We will also compare our results to those obtained previously for a data set of 11 species in the Drosophila obscura group (Snook, 1997).

These taxa differ with respect to whether the nonfertile sperm contain a normal chromosome complement. In butterflies and moths, nonfertile (apyrene) sperm have unbalanced sets of chromosomes, which are discarded before spermiogenesis is completed (Friedländer, 1977). Apyrene sperm are shorter, thinner, and contain fewer mitochondria than fertile, normally nucleated (eupyrene) sperm. Dichotomous spermatogenesis from bipotent spermatocytes is universal among the higher Lepidoptera. Apyrene sperm are often produced in large numbers (Cook and Wedell, 1999). Both morphs are found in the female spermathecae, but only eupyrene sperm fertilize eggs (Friedländer, 1977). In stalk-eyed flies (Diopsidae), 9 out of 13 species produce distinct sperm size classes. Short sperm appear normally nucleated (Daven Presgraves, personal communication), yet there is no evidence that it is capable of fertilization (Presgraves et al., 1999; Swallow and Wilkinson, 2002) and we, therefore, assume short sperm to be very likely infertile. Sex-chromosome meiotic drive occurs in some of the sperm-dimorphic species (Wilkinson et al., 1998), demonstrating the potential for haploid expression. For stalk-eyed flies (Presgraves et al., 1999), moths (Morrow and Gage, 2000) and Drosophila (Hihara and Kurokawa, 1987; Miller and Pitnick, 2002) evidence indicates that the length of the long sperm morph exhibits correlated evolution with the female reproductive tract.

The coefficient of variation is a dimensionless quantity calculated as $\mathrm{CV}=($ standard deviation $* 100) /$ mean. We use the adjusted CV that corrects for sample size differences (Sokal and Rohl 1981), defined as $\mathrm{CV}_{\mathrm{adj}}=(1+1 /$ $(4 \mathrm{n})) * \mathrm{CV}$, where $n=$ number of males. Provided that traits have the same dimensionality and complexity, the coefficient of variation is suitable to directly compare the magnitude of trait variation, because it corrects for the general tendency for morphological variance (i.e., the square of the standard deviation) to scale proportional to the square of the trait mean (Lande, 1977). Fertile sperm are longer than nonfertile sperm in all the taxa examined (see also Kura and Nakashima, 2000). Thus, if this statistical tendency alone were affecting our response variable $(\mathrm{CV})$, it would result in more variation among the longer fertile than among the shorter nonfertile sperm, contrary to our 
functional prediction that fertile sperm should vary less. Therefore, our analysis is conservative.

All studies reported standard errors $(\mathrm{SE}=$ standard deviation $/ \operatorname{sqrt}(N))$, and we obtained the standard deviation by entering the $N$ that was consistent with the original publication. In two of the studies, the SE was calculated entering male means as one observation, and in the other studies entering one value for each sperm. In two out of the three studies, exactly the same number of males had been examined for each morph within species, and in the remaining study the sample size difference was small $( \pm 2$ males) and not significant (Wilcoxon matched-pairs signed ranks-test, $z=-0.91, N=71$, $p=0.36$ ). Indeed, fertile and nonfertile sperm were measured (if available) for the same individual males. Thus, although we cannot estimate separately the variance components among sperm (within morphs within males) and among males (within morphs), the among-male variation was effectively equal for both morphs in all studies and should not affect the comparison between morphs.

The coefficient of variation is not normally distributed. Therefore, we used non-parametrical tests (Wilcoxon matched-pairs signed ranks-test comparing $\mathrm{CV}$ of fertile and nonfertile sperm size within species). The $p$-value for this test was obtained either by normal approximation or from exact probability tables, depending on the sample size (number of species), to avoid the pitfall of inappropriately applying approximated $p$-values that are only valid for large samples (Mundry and Fischer, 1998). The paired test does not correct for phylogeny. However, the test compares variation of the fertile vs. nonfertile sperm morph within species and usually within the same male. Therefore it seems unlikely that phylogeny would affect variation at the within-male level.

We carried out separate tests for each data set. To investigate whether the three separate analyses (and the effect found for each taxon separately) resulted in overall significance, we performed the Fisher combination test, a procedure for combining probabilities of a series of separate significance tests on different data sets that address the same biological hypothesis (Sokal and Rohlf, 1981, pp. 779-782).

\section{Results}

In the overall analysis of all three taxa, the fertile morphotype had a lower coefficient of total sperm length variation than the nonfertile sperm morphotype. This difference was highly significant (Fisher combination test: $-2 \sum_{\mathrm{i}} \ln \left(\mathrm{p}_{\mathrm{i}}\right)=41.22$, d.f. $=6, p<0.001$, Fig. 1). In the following we report the detailed results for each taxon separately. 


\section{Lepidoptera}

Gage (1994) reported mean sperm length for the apyrene (nonfertile) and eupyrene (fertile) sperm morph of 70 butterfly species. Standard errors were calculated using the average sperm length of each male (by morph) as one observation. The number of males examined varied among species (Table 1), but within species the same individuals were examined for fertile and nonfertile sperm. From the cumulative number of sperm measured in each species (Table 1), we estimated that across species on average $( \pm \mathrm{SD}) 4.70( \pm 2.3)$ fertile and $4.65( \pm 2.3)$ nonfertile sperm were measured per male $(N=70$ species).

The mean intraspecific coefficient of variation for total sperm length was significantly larger for the nonfertile sperm morph $\left(\mathrm{CV}_{\mathrm{adj}}=2.96 \% \pm 2.55\right)$ than for the fertile sperm morph $\left(\mathrm{CV}_{\mathrm{adj}}=2.18 \% \pm 1.84\right.$; Wilcoxon matched-pairs signed ranks-test: $z=3.39, p=0.0007$; Table 1). Thus within a given species, fertile sperm varied less in total length than nonfertile sperm (Fig. 1). Across species there was a positive significant correlation between fertile and nonfertile mean sperm length (Spearman rank correlation $r_{\mathrm{s}}=0.66, p<0.001, N=70$ ), suggesting that among-species variation in sperm length usually affected in similar ways both morphotypes. There was no significant difference in the number of

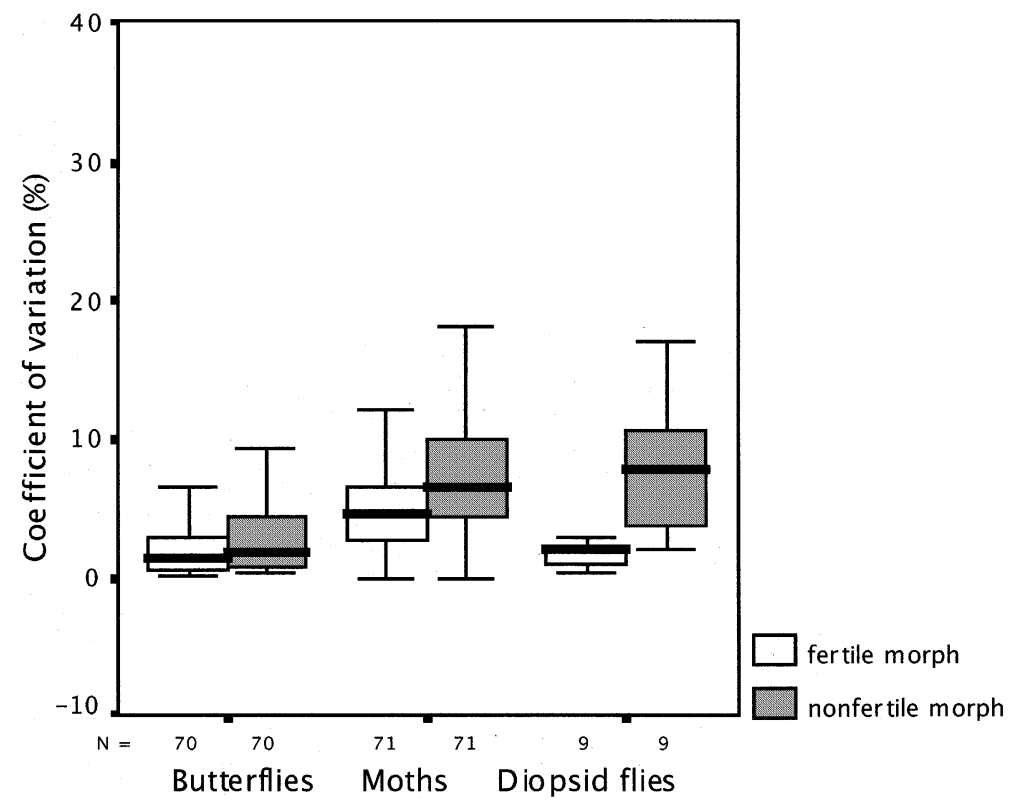

Figure 1. Adjusted coefficient of variation (\%) of total length of fertile (empty) and nonfertile (hatched) sperm in sperm-heteromorphic insects (references see Table 1). Box plot bars show the 25-percentile (lower hinge), median (thick line), and the 75-percentile (upper hinge) of a distribution. The vertical line connects minimum to maximum observed values. 
Table 1. Adjusted coefficient of variation (\%) of fertile and nonfertile sperm length within species in sperm-heteromorphic insects

\begin{tabular}{|c|c|c|c|c|c|c|c|}
\hline & $\begin{array}{l}N \\
\text { species }\end{array}$ & $\begin{array}{l}N \text { males/ } \\
\text { species }\end{array}$ & Fertile morph & $\begin{array}{l}\text { Nonfertile } \\
\text { morph }\end{array}$ & $\begin{array}{l}\text { Wilcoxon } \\
\text { test }^{2}\end{array}$ & $p$ & Ref. \\
\hline Stalk-eyed flies & 9 & $1-20$ & Long sperm & Short sperm & & & 1 \\
\hline $\mathrm{CV}$ total length & & & $2.18 \pm 1.33$ & $8.28 \pm 5.11$ & $\mathrm{~T}=44$ & 0.004 & \\
\hline$N$ sperm/male & & & $5^{1}$ & $5^{1}$ & & & \\
\hline Butterflies & 70 & $1-11$ & Eupyrene Sperm & Apyrene Sperm & & & 2 \\
\hline $\mathrm{CV}$ total length & & & $2.18 \pm 1.84$ & $2.96 \pm 2.55$ & $z=3.39$ & 0.0007 & \\
\hline$N$ sperm/species & & & $5-53$ & $4-47$ & & & \\
\hline Moths & 71 & $2-11$ & Eupyrene Sperm & Apyrene Sperm & & & 3 \\
\hline $\mathrm{CV}$ total length & & & $6.28 \pm 7.74$ & $7.71 \pm 4.59$ & $z=3.54$ & 0.0004 & \\
\hline$N$ sperm $/$ male & & & $1-5.3$ & $2-5.3$ & & & \\
\hline
\end{tabular}

Data from 1 = Presgraves et al., 1999; 2 = Gage, 1994, 3 = Morrow and Gage, 2000. Fertile sperm show significantly lower variation than nonfertile sperm.

${ }^{1} \mathrm{~N}$ sperm bundles/male.

${ }^{2}$ Test statistics: $z=$ normal approximation; $\mathrm{T}=$ exact (Mundry and Fisher, 1998; Siegel and Castellan, 1998).

sperm measured between the morphs within species (Wilcoxon matched-pairs signed ranks-test: $z=-0.31, p=0.76$ ). Thus, within a given species, there was no significant difference between morphs in the precision with which the CV had been estimated, although precision varied among species.

For moths (Morrow and Gage, 2000; untransformed data communicated by Ted Morrow) mean sperm length of apyrene (nonfertile) and eupyrene (fertile) sperm morph were available for 71 species. Standard errors were based on the average sperm length of each male (by morph) as one observation. The number of males examined varied among species, ranging between 2 and 11. Here too, the mean intraspecific coefficient of variation for total sperm length was significantly larger for the nonfertile sperm morph than for the fertile sperm morph (Table 1). Thus within a given species, nonfertile sperm varied more in total length than fertile sperm (Fig. 1). Across species there was a positive significant correlation between fertile and nonfertile mean sperm length (Spearman rank correlation $r_{\mathrm{s}}=0.66, p<0.001, N=71$ ). Within species, the number of males examined for fertile $(3.99 \pm 2.05, x \pm \mathrm{SD})$ and nonfertile sperm $(4.04 \pm 2.09)$ did not differ significantly $(p>0.20)$ thus morphological variation was estimated with equal precision for both morphs.

\section{Diptera}

In the nine sperm-heteromorphic stalk-eyed fly species, belonging to five different genera (Presgraves et al., 1999), long and short sperm bundles were 
measured in the same individual males. Standard errors were calculated for the five longest sperm bundles from each male, pooled across males. The coefficient of variation in total length among fertile sperm was significantly lower than among nonfertile sperm (Table 1, Fig. 1). This significant difference was maintained also when means and SE were calculated for male averages that included all sperm measured (not only the five longest bundles; data communicated by Daven Presgraves).

\section{Discussion}

Our meta-analysis of the intraspecific coefficient of variation of sperm length in sperm-heteromorphic insects (butterflies, moths and stalk-eyed flies) revealed that fertile sperm varied less in total length than nonfertile sperm in all groups. Not only was this difference significant in each of the three studies considered separately, it also resulted overall in a highly significant combined probability. Our results are consistent with a previous study reporting coefficients of variation of total length of short and long sperm in Drosophila obscura group (Snook, 1997, Table 3, p. 801). In that study, total length of short (i.e. nonfertile) sperm was also more variable in most species.

Several explanations may lead to this pattern. Methodological explanations include that variation can be expected to be larger for larger traits (Lande, 1977), however this clearly cannot explain our finding, because nonfertile sperm are shorter than fertile sperm (Gage, 1994; Presgraves et al., 1999; Morrow and Gage, 2000; see also Snook, 1997). A similar argument, a bias in measurement error for fertile vs. nonfertile morph, is unlikely, since to produce the observed results, such a bias would have to be substantial (up to fourfold) and to apply consistently to both Diptera and Lepidoptera, where nonfertile sperm have very different phenotypes. Further, our results may be confounded by the fact that species are treated as independent. However this is also unlikely, because our analysis addresses intraspecific differences: we used paired tests comparing variation between morphs within species, and in the majority of cases fertile and nonfertile sperm were even measured in the same individual males. Both the separate analyses of each data set and the global analysis, moreover, give the same, consistent result.

Finally, the finding that variation among a male's gametes is lower for the fertile sperm morph may have a functional explanation: relaxed selection on a fertilization-related size optimum, novel functions in nonfertile sperm, or tighter developmental control in fertile sperm. If low variation among fertile sperm were the result of stabilizing selection and optimality for fertilization, one would also predict low (at most environmental) variation among males. Data in sperm-monomorphic taxa do not support the hypothesis that sperm 
morphometry evolves solely in response to selection for the fertilization environment, because sperm length variation is generally low within males, while variation among males can be substantial (Otronen et al., 1997; Ward, 1998; Hellriegel and Bernasconi, 2000; Arnaud et al., 2001; Morrow and Gage, 2001b) and heritable (Ward, 2000). Novel functions for nonfertile sperm such as "cheap filler" in Lepidoptera (He and Miyata, 1997; Cook and Wedell, 1999; Morrow and Gage, 2000; Wedell, 2001) may be associated with increased variance, either because variation mediates the novel function, or because nonfertile sperm develop more rapidly and in a less controlled way than fertile sperm (Friedländer, 1997). Diploid control of sperm development would also be consistent with low among-sperm variation and significant, heritable between-male differences in sperm-monomorphic species. Since the sperm of a given male are genetically diverse as a result of meiosis, it has been suggested that haploid gene expression may allow individual sperm cells to gain a transmission advantage over other sperm cells of the same male (see Joseph and Kirkpatrick, 2004 for a recent review). Intra-ejaculate competition, however, may weaken the male's ability to compete with sperm of rival males (Sivinski, 1980; Haig and Bergstrom, 1995). In this scenario, selection at the male level favours suppression of post-meiotic haploid expression and diploid control of gametogenesis. In agreement with this idea, in many taxa, sperm haploid gene expression is limited or absent and sperm development and growth occur to a great extent in the primary spermatocyte, i.e. before meiosis and hence under diploid control (Parker and Begon, 1993). This potential conflict would not apply to nonfertile sperm.

In conclusion, our meta-analysis shows that low morphological variation is consistently associated with sperm fertility across three sperm-heteromorphic taxa. This finding may result from stabilizing selection for optimal sperm size, greater control of size and development in the selectively relevant sperm morph - with either congruent or conflicting interests of diploid male and haploid sperm, or novel functions favouring greater variation in nonfertile sperm. More studies are needed to clarify the consequences of sperm morphology and between- and within-male variation on male fitness.

\section{Acknowledgements}

We thank Matthew Gage, Ted Morrow, Daven Presgraves and Rhonda Snook for discussion, Ted Morrow and Daven Presgraves for kindly providing additional data, and Kevin Foster, Laurent Keller, Francis Ratnieks, Rhonda Snook, Klaus Sander, Bernhard Schmid and the referees for valuable comments on the manuscript. Grants by the Swiss Federal Program for Academic Recruitment (No. 409), Swiss NSF (3100A0-10331/1; PP00A 102 944/1) and Zurich University (Forschungskredit No. 560065) are gratefully acknowledged. 


\section{References}

Anderson, M.J. and Dixson, A.F. (2002) Motility and the midpiece in primates. Nature 416, 496.

Arnaud, L., Haubruge, E. and Gage, M.J.G. (2001) Sperm size and number variation in the red flour beetle. Zool. J. Linn. Soc. 13, 369-375.

Bernasconi, G., Ashman, T.L., Birkhead, T.R., Bishop, J.D.D., Grossniklaus, U., Kubli, E., Marshall, D.L., Schmid, B., Skogsmyr, I., Snook, R.R., Taylor, D., Till-Bottraud, I., Ward, P.I., Zeh, D. and Hellriegel, B. 2004 Evolutionary ecology of the pre-zygotic stage. Science 303, 971-975.

Briskie, J.V. and Montgomerie, R. (1992) Sperm size and sperm competition in birds. Proc. R. Soc. B. 247, 89-95.

Cook, P.A. and Wedell, N. (1999) Non-fertile sperm delay female remating. Nature 397, 486.

Dybas, L.K. and Dybas, H.S. (1981) Coadaptation and taxonomic differentiation of sperm and spermathecae in featherwing beetles. Evolution 35, 168-174.

Friedländer, M. (1997) Control of eupyrene-apyrene sperm dimorphism in Lepidoptera. J. Insect Physiol. 43, 1085-1092.

Gage, M.J.G. (1994) Associations between body size, mating pattern, testis size and sperm lengths across butterflies. Proc. R. Soc. B. 258, 247-254.

Gage, M.J.G. and Cook, P.A. (1994) Sperm size or numbers? Effects of nutritional stress upon euyprene and apyrene sperm production strategies in the moth Plodia interpunctella (Lepidoptera: Pyralidae). Func. Ecol. 8, 594-599.

Gage, M.J.G., Stockley, P. and Parker, G.A. (1998) Sperm morphometry in the Atlantic salmon. J. Fish Biol. 53, 835-840.

Haig, D. and Bergström, C. (1995) Multiple mating, sperm competition and meiotic drive. J. Evol. Biol. 8, 265-282.

He, Y. and Miyata, T. (1997) Variations in sperm number in relation to larval crowding and spermatophore size in the armyworm, Pseudaletia separata. Ecol. Entomol. 22, 41-46.

Hellriegel, B. and Bernasconi, G. (2000) Female-mediated differential sperm storage in a fly with complex spermathecae, Scatophaga stercoraria. Anim. Behav. 59, 311-317.

Hellriegel, B. and Blanckenhorn, W.U. (2002) Environmental influences on the gametic investment of yellow dung fly males. Evol. Ecol. 16, 505-522.

Hihara, F. and Kurokawa, H. (1987) The sperm length and the internal reproductive organs of Drosophila with special reference to phylogenetic relationships. Zool. Sci. 4, 167-174.

Jamieson, B.G.M. (1987) The Ultrastructure and Physiology of Insect Spermatozoa. Cambridge University Press, Cambridge, UK.

Johnson, D.D.P. and Briskie, J.V. (1999) Sperm competition and sperm length in shorebirds. Condor 101, 848-854.

Joseph, S.B. and Kirkpatrick, M. (2004) Haploid selection in animals. Trends Ecol. Evol. 19, $592-597$.

Kura, T. and Nakashima, Y. (2000) Conditions for the evolution of soldier sperm classes. Evolution 54, 72-80.

Lande, R. (1977) Comparing coefficients of variation. Syst. Zool. 26, 214-217.

Miller, G.T. and Pitnick, S. (2002) Sperm-female coevolution in Drosophila. Science 298, 1230-1233

Morrow, E.H. and Gage, M.J.G. (2000) The evolution of sperm length in moths Proc. R. Soc. B 267, 307-313.

Morrow, E.H. and Gage, M.J.G. (2001a) Sperm competition experiments between lines of crickets producing different sperm lengths. Proc. R. Soc. B 268, 2281-2286.

Morrow, E.H. and Gage, M.J.G. (2001b) Consistent significant variation between individual males in spermatozoal morphometry. J. Zool. 254, 147-153.

Mundry, R. and Fischer, J. (1998) Use of statistical programs for nonparametric tests of small samples often leads to incorrect $P$ values: examples from Animal Behaviour. Anim. Behav. 56, 256-259. 
Otronen, M., Regueira, P. and Ward, P. I. (1997) Sperm storage in the yellow dung fly Scathophaga stercoraria: identifying the sperm from competing males in separate female spermathecae. Ethology 103, 844-854.

Parker G.A. (1982) Why are there so many tiny sperm? Sperm competition and the maintenance of two sexes. J. Theor. Biol. 96, 281-294.

Parker G.A. (1990) Sperm competition games: raffles and roles. Proc. R. Soc. B. 242, 120-120.

Parker G.A. (1993) Sperm competition games: sperm size and number under adult control. Proc. $R$. Soc. B 253, 245-254.

Parker, G.A. and Begon, M.A. (1993) Sperm competition games: sperm size and number under gametic control. Proc. R. Soc. B 253, 255-262.

Presgraves, D.C., Baker, R.H. and Wilkinson, G.S. (1999) Coevolution of sperm and female reproductive tract morphology in stalk-eyed flies. Proc. R. Soc. B 266, 1041-1047.

Siegel, S. and Castellan, N.J. (1988) Nonparametric Statistics for the Behavioural Sciences. McGraw-Hill, New York, USA.

Simmons, L.W. (2001) Sperm Competition and its Evolutionary Consequences in the Insects. Monographs in Behavior and Ecology. Princeton University Press, Princeton, USA.

Sivinski, J. (1980) Sexual selection and insect sperm. Fla. Entomol. 63, 99-111

Sivinski, J. (1984) Sperm in competition. In R.L. Smith (ed.) Sperm Competition and the Evolution of Animal Mating Systems. Academic Press, New York, USA, pp. 86-115.

Snook, R.R. (1997) Is the production of multiple sperm types adaptive? Evolution 51, 797-808.

Snook, R.R. and Karr, T.L. (1998) Only long sperm are fertilization-competent in six spermheteromorphic species. Curr. Biol. 8, 291-294.

Snook, R.R. and Markow, T.A. (2002) Efficiency of gamete usage in nature: sperm storage, fertilization and polyspermy. Proc. R. Soc. B 269, 467-473.

Sokal, R.R. and Rohlf, F.J. (1981) Biometry. Freeman \& Co., London, UK.

Swallow, J.G. and Wilkinson, G.S. (2002) The long and short of sperm polymorphism in insects. Biol. Rev. 77, 153-182.

Ward, P.I. (1998) Intraspecific variation in sperm size characters. Heredity 80, 655-659.

Ward, P.I. (2000) Sperm length is heritable and sex-linked in the yellow dung fly Scathophaga stercoraria. J. Zool. 251, 349-353.

Wedell, N. (2001) Female remating in butterflies: interaction between female genotype and nonfertile sperm. J. Evol. Biol. 14, 746-754.

Wilkinson, G.S. and Fry, C.L. (2001) Meiotic drive alters sperm competitive ability in stalk-eyed flies Proc. R. Soc. B 268, 2559-2564. 